\title{
SOLUTION OF OPTIMIZATION PROBLEMS OF HIGH-INERTIAL ASYNCHRONOUS ELECTRIC DRIVE
}

\author{
Murot Tulyaganov ${ }^{1}$ \\ ${ }^{1}$ Tashkent State technical university, Department of Electromechanics and Electrotechnologies, Universitetskaya -2 , \\ Tashkent, 100095, Uzbekistan
}

\begin{abstract}
The method of optimum start-up calculation on computer with use of the principle of a maximum and Newton-Rafson's method for the high-inertial asynchronous electric drive is offered. Based on this technique, optimal dynamic modes of high-inertia frequency-controlled asynchronous electric drive are calculated taking into account thermal processes. Methods of increasing electric motor energy efficiency due to reducing power consumption in dynamic modes are considered.
\end{abstract}

The problem of the operating modes optimizing of electromechanical systems for a long time is in the center of attention of specialists. Physical processes that occur in electromechanical objects, as a rule, are controlled, they are implemented in various ways depending on the requirements of the technological process. In this regard, the problem arises of finding the best mode on the basis of optimal process control, which provides improved technical and economic indicators of the facility. For example, a performance optimality criterion that achieves a process goal in the shortest time or with minimal energy consumption. Such issues are tasks of optimal control [1-5].

In the sectors of the national economy, a number of asynchronous electric drives operate in heavy start-brake modes. These include high-inertial electric drives, for example, turbomolecular pumps, lifting and transportation mechanisms, balancing machines, highspeed centrifuges, centrifugal separators, gas turbines, mechanical energy accumulators, and others. The peculiarity of such mechanisms is the long start-up process. Due to the large losses in the process of starting high-inertial mechanisms, a significant amount of thermal energy is released, an unacceptable overheating of the asynchronous motor insulation occurs and the engine can break down. In this regard, an important scientific and technical task arises: reducing losses in the transition process and increasing the speed of highinertial asynchronous electric drives. One promising way to solve this problem is to determine the optimal control effects based on the use of mathematical models and using the theory of optimal control [6-9].

One of the most effective methods of researching problems of optimal control of dynamics of high-inertial automated frequency-controlled electric drives consists in their mathematical modeling on computers, finding optimal control laws for evaluating their limit capabilities and improving the adjustment, energy and operational characteristics of the electric drive.
Let's consider a system of integral equations, describing the joint electromechanical and thermal processes that take place in a high-inertial frequency-controlled asynchronous electric drive and add speed functionality to them:

$$
\left.\begin{array}{c}
\theta_{\partial}=\int_{t_{0}}^{T}\left(\frac{P_{h}}{C_{i}}+k_{1} \theta_{0}-k_{2} \theta_{d}\right) d t \\
\omega=\int_{t_{0}}^{T}\left(\frac{p}{J}\left(M_{e}-M_{s}\right)\right) d t \\
J_{T}=\int_{t_{0}}^{T} d t
\end{array}\right\},(1)
$$

where $\theta_{0}$ - average temperature, $\omega$ - angular speed of shaft rotation, $C_{i}$ - engine heat capacity, $k_{1}, k_{2}$ coefficients reflecting the thermal connection of the motor with the environment, $p$ - number of pairs of motor poles, $J$ - inertia torque of rotating parts of asynchronous motor, $M_{e}$ - electromagnetic torque, $M_{s}$ static torque on the shaft.

A generalized mathematical model (1) in which an asynchronous motor is considered as a single homogeneous body, taking into account the mutual influence of all parameters, includes two integral equations: the first is the thermal balance of the asynchronous motor with the environment, the second is the equation of motion of the electric drive. Heat equations in the system of equations (1) are written on the basis of the classical theory of non-stationary heat exchange. [10-14]

Electrical losses in stator and rotor windings of asynchronous motor $\left(P_{h}\right)$ are taken as heat losses during transient process. [15-17]

Convert the system (1):

$$
\begin{aligned}
& \theta_{\partial}=\int_{t_{0}}^{T}\left[m_{1} \Phi^{2} C_{k}^{2} f_{1 \mathrm{H}}^{2} \frac{\left(r_{1}+\frac{r_{1} x \gamma^{2}}{x_{0}}\right)^{2} \beta^{2}+\frac{r_{1}^{2} x \prime^{2}}{x_{0}^{2}}+r_{1} r_{2} \beta^{2}}{r_{1}\left(x \prime_{2}^{2} \beta^{2}+r r_{2}^{\prime}\right)}+k_{1} \theta_{0}-k_{2} \theta_{\partial}\right] d t \\
& \omega=\int_{t_{0}}^{T} \frac{p}{J}\left(\frac{p m_{1} \Phi^{2} C_{k}^{2} f_{1 \mathrm{H}}^{2} r r_{2} \beta}{\omega_{1 \mathrm{H}}\left(x r_{2}^{2} \beta^{2}+r_{2}^{\prime}\right)}-M_{S}\right) d t \\
& J_{T}=\int_{t_{0}}^{T} d t
\end{aligned}
$$

The basis for writing equations (2) was the positions [2]. 
The following designations are accepted here: $\beta$ relative parameter of absolute slip, $m_{1}$ - number of phases, $r_{1}$ - stator active resistance, $r^{\prime}{ }_{2}$ - rotor active resistance, $x_{1}, x_{2}, x_{0}$ - inductive resistance of stator, rotor and magnetizing circuit, $\Phi$ - magnetic flux in air gap, $C_{k}$ - constructive constant of the asynchronous motor, $f_{1 \mathrm{H}}$ - nominal frequency of asynchronous motor power supply, $\omega_{1}$ - angular speed of stator field rotation. We find the coordinates and optimal control effects of the electric drive, while minimizing the average heating temperature of the asynchronous motor [19-21].

We will find coordinates and optimal control effects of the electric drive, while minimizing the average heating temperature of the asynchronous motor.

Minimization $\theta_{\partial}$ is associated with minimization of stator and rotor current of asynchronous motor. The electrical losses in these windings in the transient process are the main losses and accordingly equal to $m_{1} I_{2}^{\prime 2} r^{\prime}{ }_{1}$ and $m_{1} I_{2}^{\prime 2} r_{2}^{\prime}$. [2] This setting of the task is a development of the law of frequency control to the minimum square of the stator current of the asynchronous motor. [22-23]

Not accounting of saturation of steel of a magnetic conductor of the asynchronous motor leads to essential mistakes in calculations therefore it is necessary to consider saturation. To do this, we use the Arkhangelsk formula, which expresses the flow through the magnetization current [3]:

$$
\Phi=A \cdot \operatorname{arctg} B i_{0},(3)
$$

where $\mathrm{A}$ and $\mathrm{B}$ - approximation factors. The resistance of the magnetizing circuit $x_{0}$ (included in the formulas of the mathematical model) is calculated as follows

$$
x_{0}=b-c \Phi^{2},(4)
$$

where $\mathrm{b}$ and $\mathrm{c}$ - constant coefficients

To solve the problem (2), first use the principle of maximum [4]. According to the principle of maximum, the equation (2) is supplemented by an auxiliary, socalled conjugate system $\bar{\psi}$. Then we compose the Hamilton intermediate function $\mathrm{H}$. The $\max \mathrm{H}$ requirement is a prerequisite for optimality.

As controls, take intermediate variables: absolute sliding parameter $\beta$ and $x_{0}$. To do this, take the partial derivatives from the intermediate function $\mathrm{H}$ of $\beta$ and $x_{0}$, equate them to zero.

If we enter symbols:

$k_{5}=r_{1}^{2} r_{2}^{\prime} k_{3} \psi_{1}\left(1+\frac{2 x_{2}}{x_{0}}+\frac{r_{2}}{x_{0}}\right), \quad k_{6}=\left(x_{2}^{\prime} r_{2}^{\prime} k_{4} \psi_{2}\right)^{2}$, $k_{7}=-x^{\prime}{ }_{2} k_{4} \psi_{2}$,

$a_{1}=-\beta\left(\psi_{1} k_{3} \beta r_{1}^{2}+k_{4} \psi_{2}+r_{1} r_{2}^{\prime 2} \beta \psi_{1} k_{3}\right), a_{2}=0$,

$a_{3}=\psi_{1} k_{3} r_{1}^{2}\left(x_{2}^{\prime 2} \beta-2 \beta b x_{2}^{\prime}+r_{2}^{\prime 2}\right)$,

$a_{4}=-2 r_{1}^{2} b k_{3} \psi_{1}\left(r_{2}^{\prime 2}+\beta^{2} x_{2}^{\prime 2}\right)$,

$F\left(\bar{A}, \overline{x_{0}}\right)=a_{1} x_{0}^{3}+a_{2} x_{0}^{2}+a_{3} x_{0}+a_{4}$,

$\bar{A}=\left[a_{1}, a_{2}, a_{3}, a_{4}\right]$,

as a result, it is possible to write a finally edge point-topoint problem, the solution of which will determine the optimal control effects of a frequency-controlled asynchronous motor with constant resistance moment on its shaft:

$$
\left.\begin{array}{c}
\frac{d \theta_{\partial}}{d t}=k_{3} \frac{b-x_{0}}{c} \cdot \frac{\left(r_{1}+\frac{r_{1} x_{2}^{\prime} 2}{x_{0}}\right)^{2} \beta^{2}+\frac{r_{1}^{2} x^{\prime 2}}{x_{0}^{2}}+r_{1} r_{2} \beta^{2}}{r_{1}\left(x_{2}^{\prime 2} \beta^{2}+r^{\prime 2}\right)}+k_{1} \theta_{0}-k_{2} \theta_{\partial} \\
\frac{d \omega}{d t}=k_{4} \frac{\left(b-x_{0}\right) \beta}{x_{2}^{\prime 2} \beta^{2}+r^{\prime 2}}-\frac{p}{J} M_{S} \\
\frac{d \psi_{1}}{d t}=k_{2} \psi_{1} \\
\frac{d \psi_{2}}{d t}=0 \\
\beta^{*}=\frac{-k_{5} \pm \sqrt{k_{5}^{2}+k_{6}}}{k_{7}} \\
F\left(\bar{A}, x_{0}^{*}\right)=0
\end{array}\right\}
$$

Boundary conditions:

$\theta_{\partial(t=0)}=\theta_{\partial 0} ; \theta_{\partial(t=T)}=\theta_{\partial T} ;$

$\omega_{(t=0)}=\omega_{0} ; \omega_{(t=T)}=\omega_{T}$.

Next, we solve the problem on a computer using the Newton-Raphson method [5]. According to the above algorithm [5], the optimal launches of ADAE92-4 with power of $40 \mathrm{~kW}$, a protected version with a high moment of inertia were calculated in accordance with the criterion of optimality in terms of minimum electrical losses, taking into account saturation. When calculating, the total moment of inertia of the working mechanism and rotating parts of the asynchronous motor was almost 17 times higher than the own moment of inertia of the rotor.

Graphs of key parameters of start-up with a nominal frequency and optimum start-up for zero entry conditions of coordinates in relative units are provided respectively on fig. 1 and fig. 2 .

Curves 1 in Fig. 2 correspond to frequency control for criterion of optimum minimum electrical losses in stator and rotor of asynchronous motor, curves 2 - for criterion of minimum electrical losses only in stator of asynchronous motor.

To give a quantitative assessment to the chosen mode, results of calculation it is comparable to results of the mode of start-up with a nominal frequency. Asynchronous motor parameters are taken as basic parameters in nominal operation mode, except for average temperature. Average heating temperature of asynchronous motor at the end of transient process at starting from cold state to nominal speed of rotation with nominal frequency is taken as basic heating temperature. As can be seen from the graphs (Fig.1, 2) for ADAE924 , the average temperature of the mode of minimum electrical losses in the stator and rotor of the asynchronous motor can be reduced theoretically by almost $77 \%$ with respect to the start of the asynchronous motor at the nominal frequency [24].

Assuming that the transient ends at $\tau=t / t_{i}=1$, and the value of all electromechanical and thermal dependencies of the mode according to the minimum electrical losses in the stator and rotor should be taken as $100 \%$, it can be noted that at optimal frequency start-up by minimum of electric losses in stator and rotor upon reaching nominal rotation speed $\mathrm{n}=1405 \mathrm{rpm}$, relative parameter of absolute sliding $\beta$ during the same start-up time differs from value $\beta$ of mode by minimum of electric losses in stator of asynchronous motor by $23.1 \%$; relative supply voltage of the asynchronous motor $\gamma$ from the mode value $\gamma$ by minimum electric losses in the stator - by $7.3 \%$; stator current - by $6.6 \%$; relative 
frequency of asynchronous motor - by $1.8 \%$; losses in steel - by $15.3 \%$; copper losses and the average temperature of the asynchronous motor - by $67.3 \%$ upward. Angular speed of shaft rotation and electromagnetic torques of both modes coincide [25-28]. From the above it follows that the mode of minimum electrical losses in the stator and rotor differs from the mode of minimum electrical losses in the stator by an amount characterizing additional accounting of electrical losses in the rotor winding of the asynchronous motor. Thus, in high-efficiency electric drives with asynchronous motors, accounting for electrical losses in the rotor winding will avoid extremely undesirable overheating of the limiting parts of the asynchronous motor and most fully use the motor by heat.

As can be seen from the graph (Fig.2), the optimal control law assumes the character of the change in rotation speed as monotonous and close to linear. This means that by stabilizing the acceleration in the transition process, high technical and economic performance of the electric drive can be obtained [29$30]$.

The proposed method and algorithm for calculating optimal launches, and the obtained laws of control actions make it possible to formulate specific requirements for automatic control and control systems of frequency electric drive, which implement optimal dynamic modes.

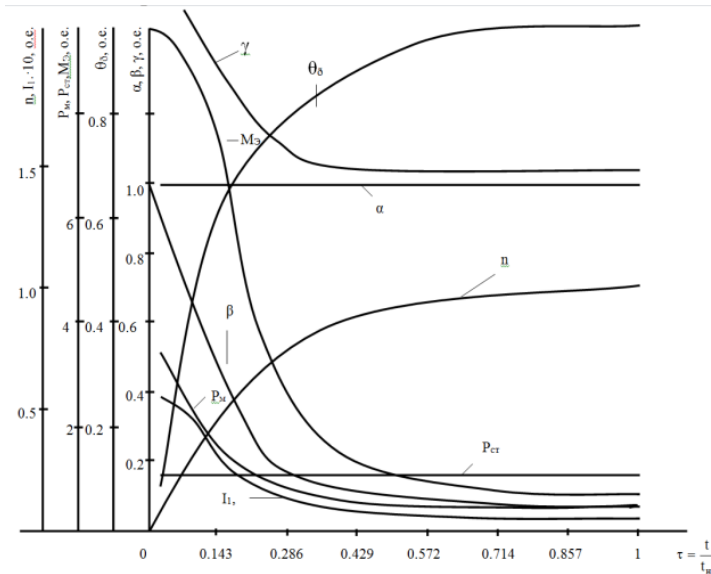

Fig.1. Start-up ADAE-92-402 at nominal power supply frequency

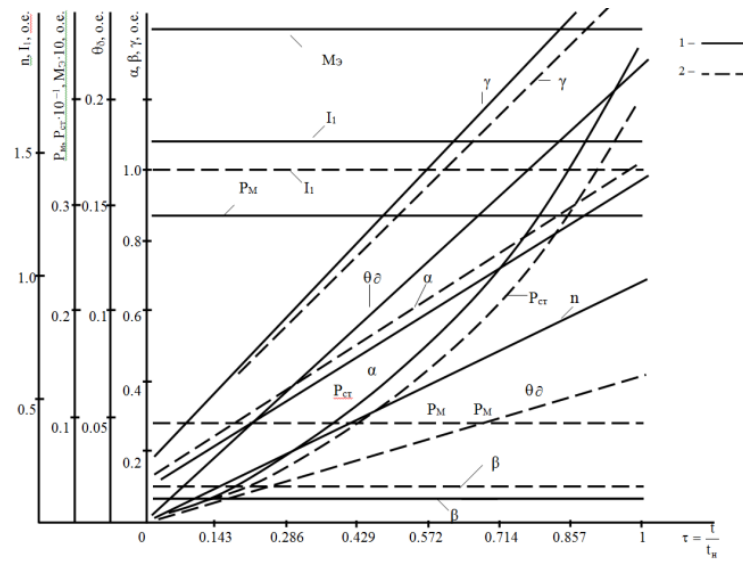

Fig. 2. Curves of optimal ADAE92-4 starts in frequency-controlled electric drive systems

\section{References}

1. Bolyaev I.P. Calculation of thermal processes in electrical machines on an electronic model. Electromechanics, 1961, No. 8, p.22-39.

2. Bulgakov A.A. Frequency control of asynchronous motors. M.: Energoizdat, 1982, 216 p.

3. Shubenko V.A., Schreiner R.T., Mishchenko V.A. Optimization of frequency-controlled asynchronous electric drive by minimum current. Electricity, 1970, No. 9, p.23-25.

4. Pontryagin L.S., Boltyansky V.G., Gamkrelidze R.V., Mishchenko E.F. Mathematical theory of optimal processes. M.: Fizmatgiz, 1961, 391 p.

5. Khashimov A.A., Tulyaganov M.M., Petrushin A.D. Application of the Newton-Raphson method for solving optimization problems of frequency-controlled asynchronous electric drive. Applied issues of electroautomatics and conversion technology. Scientific works TashPI, Tashkent, 1986, p.25-30.

6. Saidkhodjaev A G, Najimova A M and Bijanov A K 2019 Method for determining the maximum load of consumers in city power supply systems E3S Web Conf 139 doi:10.1051/e3sconf/201913901078.

7. Taslimov A D, Rakhmonov I U 2019 Optimization of complex parameters of urban distribution electric networks Journal of Physics: Conference Series 1399 doi:10.1088/1742-6596/1399/5/055046

8. Rakhmonov I U, Niyozov N N 2019 Optimization setting of steel-smelting industry in the issue of alloy steels E3S Web Conf 139 doi:10.1051/e3sconf/201913901077

9. Rakhmonov I U, Tovbaev A N, Nematov L A and Alibekova T Sh 2020 Development of forecasted values of specific norms for the issues of produced products in industrial enterprises Journal of Physics: Conference Series 1515 doi:10.1088/1742-6596/1515/2/022050

10. Rakhmonov I U, Nematov L A, Niyozov N N, Reymov K M and Yuldoshev T M 2020 Power consumption management from the positions of the general system theory Journal of Physics: Conference Series 1515 doi:10.1088/1742-6596/1515/2/022054

11. Rakhmonov I U, Reymov K M, Najimova A M, Uzakov B T and Seytmuratov BT 2019 Analysis and calculation of optimum parameters of electric arc furnace Journal of Physics: Conference Series 1399 doi:10.1088/1742-6596/1399/5/055048

12. Taslimov A D, Berdishev A S, Melikuzuev M V and Rakhimov F M 2019 Method of selecting parameters of cable lines distributive networks $10 \mathrm{kv}$ in uncertainty conditions E3S Web 139 doi:10.1051/e3sconf/201913901082

13. Taslimov A D, Berdishev A S, Melikuziyev M V and Rakhimov F M 2019 Method of choosing the unification of cable sections of electric network cables under conditions of load development uncertainty E3S Web Conf 139 doi:10.1051/e3sconf/201913901081

14. Rakhmonov, I.U., Berdishev, A.A., Khusanov, B.M., Khaliknazarov, U., Utegenov, U. (2020) General characteristics of networks and features of electricity consumers in rural areas Journal of IOP: Conference 
Series. MIP: Engineering-2020. 883 (2020) 012104 doi:10.1088/1757-899X/883/1/012104

15. Karimov R.Ch., Shamsiyev K., and others. IOP Conf. Series: Materials Science and Engineering, 883(1), 012142, (2020). doi:10.1088/1757-899X/883/1/012142

16. Karimov R.Ch., Shamsiyeva N. and others. IOP Conf. Series: Materials Science and Engineering, 883(1), 012120, (2020). doi:10.1088/1757-899X/883/1/012120

17.E.G.Usmanov, A.N.Rasulov, M.K.Bobojanov, R.Ch.Karimov. E3S Web of Conferences 139, 01079 (2019), doi.org/10.1051/e3sconf/201913901079

18. Bobojanov M.K., Rasulov A.N., Karimov R.Ch., Sattarov H.A. Bulletin Descendants of Mohammed AlKhwarizmi (ISSN: 2181-9211), Tashkent, 3(5), PP.106-109, (2018).

19. Burievich, T.J. The questions of the dynamics of drilling bit on the surface of well bottom// Arch. Min. Sci. -Poland. - Vol. 61 (2016). - №2 . - P. 279-287. DOI 10.1515/amsc-2016-0020.

20. Toshniyozov, L.G., Toshov, J.B. Theoretical and experimental research into process of packing in drilling// Mining Informational and Analytical Bulletin Volume 2019, Issue 11, 2019, Pages 139-151. DOI: 10.25018/0236-1493-2019-11-0-139-151.

21. Hoshimov, F.A., Bakhadirov, I.I., Erejepov, M., Djumamuratov, B. (2019) Development of method for normalizing electricity consumption E3S Web Conf 139 doi:10.1051/e3sconf/201913901074

22. G.R.Rafikova, M.R.Ruzinazarov, S.K.Makhmutkhonov. E3S Web of Conferences, 139, 01075,

(2019),

https://doi.org/10.1051/e3sconf/201913901075

23. Safarov J.E., Sultanova Sh.A., Dadayev G.T., Samandarov D.I. Method for drying fruits of rose hips. // International Journal of Innovative Technology and Exploring Engineering. Vol.9, Iss.1. 2019. P.3765-3768, 24. Safarov J.E., Sultanova Sh.A., Dadayev G.T., Samandarov D.I. Method for the primary processing of silkworm cocoons (Bombyx mori). // International Journal of Innovative Technology and Exploring Engineering. Volume-9, Issue-1, November, 2019. P.4562-4565.

25. Allayev, K.R., Fedorenko, G.M.,Postnikov, V.I.,Ostapchuk, L.B. Asynchronous generators as power system's natural dampers. 43rd International Conference on Large High Voltage Electric Systems 2010, CIGRE 20102010, 9p43rd International Conference on Large High Voltage Electric Systems 2010, CIGRE 2010; Paris; France; 22 August 2010.

26.Fazylov, Kh.F.,Allaev, K.R. Analysis of the operation of an electrical system during simultaneous operation of synchronous and asynchronous generators. Power engineering New York Volume 18, Issue 3, 1980, Pages 81-88.

27.Fazylov, Kh.F.,Allaev, K.R. Asynchronous turbogenerators with stator excitation and the prospects for their utilization. Power engineering New York Volume 23, Issue 2, 1985, Pages 7-13.

28.Fazylov, Kh.F.,Allaev, K.R. Calculation and experimental analysis of conditions of electrical power systems containing induction generators Power Engineering New York Volume 27, Issue 6, 1989, Pages 27-34.

29.Allaev K., Makhmudov T. Research of small oscillations of electrical power systems using the technology of embedding systems. Electrical Engineering, 2020; Issue 1: 309-319.DOI 10.1007/s00202-019-00876-9

30.Allaev K., Makhmudov T. Prospects of diversification and ensuring energy safety of Uzbekistan. E3S Web Conf., Volume 139, 2019, Rudenko International Conference "Methodological problems in reliability study of large energy systems" (RSES 2019).https://doi.org/10.1051/e3sconf/201913901002 